\title{
1-1-8 one-step sevoflurane wash-in scheme for low-flow anesthesia: simple, rapid, and predictable induction
}

\author{
Sirirat Tribuddharat, Thepakorn Sathitkarnmanee* (D), Naruemon Vattanasiriporn, Maneerat Thananun, \\ Duangthida Nonlhaopol and Wilawan Somdee
}

\begin{abstract}
Background: Sevoflurane is suitable for low-flow anesthesia (LFA). LFA needs a wash-in phase. The reported sevoflurane wash-in schemes lack simplicity, target coverage, and applicability. We proposed a one-step 1-1-8 washin scheme for sevoflurane LFA to be used with both $\mathrm{N}_{2} \mathrm{O}$ and Air. The objective of our study was to identify time for achieving each level of alveolar concentration of sevoflurane $\left(F_{A} S\right)$ from 1 to $3.5 \%$ in both contexts.

Methods: We recruited 199 adults requiring general anesthesia with endotracheal intubation and controlled ventilation-102 in group $\mathrm{N}_{2} \mathrm{O}$ and 97 in group Air. After induction and intubation, a wash-in was started using a fresh gas flow of $\mathrm{O}_{2}: \mathrm{N}_{2} \mathrm{O}$ or $\mathrm{O}_{2}$ :Air at 1:1 L.min ${ }^{-1}$ plus sevoflurane $8 \%$. The ventilation was controlled to maintain end-tidal $\mathrm{CO}_{2}$ of $30-35 \mathrm{mmHg}$.

Results: The rising patterns of $F_{A} S$ and inspired concentration of sevoflurane $\left(F_{S} S\right)$ are similar, running parallel between the groups. The $F_{A} S / F_{1} S$ ratio increased from 0.46 to 0.72 within $260 \mathrm{~s}$ in group $\mathrm{N}_{2} \mathrm{O}$ and from 0.42 to 0.69 within $286 \mathrm{~s}$ in group Air. The respective time to achieve an $\mathrm{F}_{\mathrm{A}} \mathrm{S}$ of $1,1.5,2,2.5,3$, and 3.5\% was 1, 1.5, 2, 3, 3.5, and 4.5 min in group $\mathrm{N}_{2} \mathrm{O}$ and $1,1.5,2,3,4$, and $5 \mathrm{~min}$ in group Air. The heart rate and blood pressure of both groups significantly increased initially then gradually decreased as $F_{A} S$ increased.

Conclusions: The 1-1-8 wash-in scheme for sevoflurane LFA has many advantages, including simplicity, coverage, swiftness, safety, economy, and that it can be used with both $\mathrm{N}_{2} \mathrm{O}$ and Air. A respective $\mathrm{F}_{\mathrm{A}} \mathrm{S}$ of $1,1.5,2,2.5,3$, and 3.5\% when used with $\mathrm{N}_{2} \mathrm{O}$ and Air can be expected at 1, 1.5, 2, 3, 3.5, and $4.5 \mathrm{~min}$ and 1, 1.5, 2, 3, 4, and 5 min.
\end{abstract}

Trial registration: This study was retrospectively registered with ClinicalTrials.gov (NCT03510013) on June 8, 2018.

Keywords: Wash-in, Low flow anesthesia, Nitrous oxide, Air, Sevoflurane

\section{Background}

Low-flow anesthesia (LFA; fresh gas flow $(\mathrm{FGF}) \leq 1$ $\left.\mathrm{L} \cdot \mathrm{min}^{-1}\right)$ is gaining in popularity because it has a relatively lower cost, causes less environmental burden, and medically because it increases the humidity and temperature of inspired gas, leading to improved mucociliary function of the patient [1]. Since use of low FGF leads to a long time constant, a wash-in phase using a high FGF and high vaporizer concentration of volatile anesthetic $\left(\mathrm{F}_{\mathrm{V}}\right)$ is warranted in order to rapidly achieve the required concentration of inhalation anesthetic in

\footnotetext{
*Correspondence: thepakorns@gmail.com

Department of Anesthesiology, Faculty of Medicine, Khon Kaen University, 123 Mitrapap road, Ampur Muang, Khon Kaen 40002, Thailand
}

the breathing system. Sevoflurane-when used with strong base-free $\mathrm{CO}_{2}$ absorbent-is suitable for use in LFA because it has low blood-gas solubility. The minimum alveolar concentration (MAC) of sevoflurane varies with patient age-from $1.4 \%$ at age 80 to $2.3 \%$ at age 1 year [2]. The optimal alveolar concentration of sevoflurane $\left(\mathrm{F}_{\mathrm{A}} \mathrm{S}\right)$ to prevent motor movement and autonomic response during anesthesia is MAC-Bar which approximates 1.5 MAC. Thus, the target of $\mathrm{F}_{\mathrm{A}} \mathrm{S}$ during anesthesia in daily practice varies between 1 to $3.5 \%$, depending on the adjuvant drugs used. A good wash-in scheme should be able to precisely and promptly achieve every target of $\mathrm{F}_{\mathrm{A}} \mathrm{S}$. There are a few reports regarding wash-in schemes of sevoflurane LFA but those studies

(c) The Author(s). 2020 Open Access This article is distributed under the terms of the Creative Commons Attribution 4.0 International License (http://creativecommons.org/licenses/by/4.0/), which permits unrestricted use, distribution, and 
achieved only one or two targets of $\mathrm{F}_{\mathrm{A}} \mathrm{S}$ [3-5]. In highly developed healthcare areas-where an anesthetic gas monitor is placed in every operating theatre-a wash-in scheme would be unnecessary. By contrast, in less developed areas where anesthetic gas monitors are rare or nonexistent, a precise and reliable wash-in scheme is mandatory for sevoflurane LFA. Since the carrier gases used in anesthesia comprise both $\mathrm{O}_{2}$ plus $\mathrm{N}_{2} \mathrm{O}$ and $\mathrm{O}_{2}$ plus Air, we propose a simple one-step 1-1-8 wash-in scheme for sevoflurane LFA using FGF of $2 \mathrm{~L} \cdot \mathrm{min}^{-1}$ by combining $\mathrm{O}_{2}$ with $\mathrm{N}_{2} \mathrm{O}$ or Air at 1:1 L.min ${ }^{-1}$ and a $\mathrm{F}_{\mathrm{V}}$ of sevoflurane $\left(\mathrm{F}_{\mathrm{V}} \mathrm{S}\right) 8 \%$, which can be used to estimate the time to achieve each $\mathrm{F}_{\mathrm{A}} \mathrm{S}$ in daily practice. The hypothesis is that this scheme can precisely and promptly achieve every $\mathrm{F}_{\mathrm{A}} \mathrm{S}$ from 1 to $3.5 \%$ within 5 min.

The primary outcome of the current study was the time to achieve a $\mathrm{F}_{\mathrm{A}} \mathrm{S}$ of $1,1.5,2,2.5,3$, and $3.5 \%$ in both contexts. The secondary outcomes were to identify the changes in heart rate and blood pressure during wash-in.

\section{Methods}

The current study was approved by the Khon Kaen University Ethics Committee in Human Research (HE601228) and was registered with ClinicalTrials.gov (NCT03510013). The study was conducted in accordance with Declaration of Helsinki and the ICH GCP. All participants gave written informed consent before being recruited into the study.

This was a prospective, descriptive study. We aimed to recruit two groups of patients: group $\mathrm{N}_{2} \mathrm{O}$ and group Air. We calculated the sample size from a pilot study on 20 patients, which identified a standard deviation of $40 \mathrm{~s}$ at an $\mathrm{F}_{\mathrm{A}} \mathrm{S}$ of $3.5 \%$. With the total width of the expected confidence interval of $16 \mathrm{~s}$, and a significance criterion of 0.05 , the total number of patients required was 96 . The inclusion criteria were adult patients, between 18 and 64, with an American Society of Anesthesiologists (ASA) physical status of 1-2, undergoing elective surgery under general anesthesia at Srinagarind Hospital, Khon Kaen University, Khon Kaen, Thailand. The exclusion criteria were patients with a BMI $>30 \mathrm{~kg} \cdot \mathrm{m}^{-2}$; a contraindication for $\mathrm{N}_{2} \mathrm{O}$ or succinylcholine; having pulmonary or cardiac disease; or, being pregnant.

All patients received standard intra-operative anesthetic monitoring and care. The monitoring included electrocardiogram, pulse oximetry, non-invasive blood pressure measurement, capnography, and MAC value. The anesthetic machine-with an integrated anesthetic gas analyzer used in this study was the Dräger Primus (Dräger AG, Lübeck, Germany). We used a standard circle circuit with Litholyme as the $\mathrm{CO}_{2}$ absorbent. Heart rate and blood pressure were recorded as baseline parameters before induction of anesthesia. After pre-oxygenation for $3 \mathrm{~min}$, each patient was premedicated with fentanyl $1-2 \mu \mathrm{g} \cdot \mathrm{kg}^{-1}$, then propofol $2 \mathrm{mg} \cdot \mathrm{kg}^{-1}$ was given as the induction agent. Endotracheal intubation was facilitated with succinylcholine $1.5 \mathrm{mg} \cdot \mathrm{kg}^{-1}$. After a correct endotracheal tube position was confirmed, cisatracurium $0.15 \mathrm{mg} \cdot \mathrm{kg}^{-1}$ was given.

\section{Group $\mathrm{N}_{2} \mathrm{O}$}

The ventilation was controlled using $\mathrm{O}_{2}: \mathrm{N}_{2} \mathrm{O}$ at $1: 1$ $\mathrm{L} \cdot \mathrm{min}^{-1}$ and $\mathrm{F}_{\mathrm{V}} \mathrm{S}$ of $8 \%$. The ventilator was set at volume-control with an inspiratory:expiratory (I:E) ratio of $1: 2$, a positive end-expiratory pressure (PEEP) of 0 , and a tidal volume of $8 \mathrm{~mL} \cdot \mathrm{kg}^{-1}$ with a respiratory rate of $12 \mathrm{~min}^{-1}$-which was adjusted periodically to achieve an end-tidal $\mathrm{CO}_{2}$ of $30-35 \mathrm{mmHg}$. The times to achieve a respective $\mathrm{F}_{\mathrm{A}} \mathrm{S}$ of $1,1.5,2,2.5,3$, and $3.5 \%$ were recorded as the primary outcome. The inspired concentration of sevoflurane $\left(\mathrm{F}_{\mathrm{I}} \mathrm{S}\right)$, heart rate, and blood pressure at each $\mathrm{F}_{\mathrm{A}} \mathrm{S}$ were recorded as the secondary outcomes. When the $F_{A} S$ reached $3.5 \%$, the FGF was reduced to 1 $\mathrm{L} \cdot \mathrm{min}^{-1}$ and the $\mathrm{F}_{\mathrm{V}} \mathrm{S}$ readjusted at the discretion of the attending anesthesiologist. Surgery started after completion of recording the study parameters.

\section{Group air}

The same procedure was used except using $\mathrm{O}_{2}$ :Air at 1 : $1 \mathrm{~L} \cdot \mathrm{min}^{-1}$ and $\mathrm{F}_{\mathrm{V}} \mathrm{S}$ of $8 \%$.

\section{Statistical analysis}

Continuous data were presented as means \pm standard deviation (SD) while categorical data were presented as numbers (\%). The primary outcomes were presented as means \pm SD with a $95 \%$ confidence interval (CI). The secondary outcomes (viz., heart rate and blood pressure at different time points) were compared using repeated measures analysis of variance. A $P<0.05$ was considered statistically significant. All data were analyzed using SPSS 16.0 (SPSS Inc., Chicago, IL, USA).

\section{Results}

A total of 199 patients were recruited between September and December 2018-102 in group $\mathrm{N}_{2} \mathrm{O}$ and 97 in group Air. The patient and clinical characteristics are presented in Table 1. The trajectories of time to achieve each $F_{A} S$ for all patients of group $\mathrm{N}_{2} \mathrm{O}$ and group Air are presented in Figs. 1 and 2. The gradual rising pattern of $F_{A} S$ and $F_{I} S$ are similar and parallel in both groups (Fig. 3). The ratio of $\mathrm{F}_{\mathrm{A}} \mathrm{S} / \mathrm{F}_{\mathrm{I}} \mathrm{S}$ of both groups rises rapidly from 0.46 to 0.72 within $260 \mathrm{~s}$ for group $\mathrm{N}_{2} \mathrm{O}$ and 0.42 to 0.69 within $286 \mathrm{~s}$ in group Air (Fig. 4). The respective time to achieve a $F_{A} S$ of $1,1.5,2,2.5,3$, and $3.5 \%$ (in sec) with $95 \% \mathrm{CI}$ and the approximate upper limit of the 95\% CI (in min) of group $\mathrm{N}_{2} \mathrm{O}$ and group Air are presented in Tables 2 and 3. A $\mathrm{F}_{\mathrm{A}} \mathrm{S}$ of $3.5 \%$ can be achieved within $4.5 \mathrm{~min}$ in group $\mathrm{N}_{2} \mathrm{O}$ and $5 \mathrm{~min}$ in group Air. The heart rate and blood pressure 
Table 1 Patient and clinical characteristics

\begin{tabular}{lll}
\hline Parameter & Nitrous oxide $(n=102)$ & Air $(n=97)$ \\
\hline Age (years) & $42.5 \pm 12.7$ & $46.0 \pm 12.1$ \\
Weight $(\mathrm{kg})$ & $58.6 \pm 10.0$ & $58.4 \pm 9.9$ \\
Height $(\mathrm{cm})$ & $159.8 \pm 6.4$ & $160.3 \pm 7.7$ \\
Sex & & \\
$\quad$ Male & $22(21.6)$ & $24(24.7)$ \\
$\quad$ Female & $80(78.4)$ & $73(75.3)$ \\
ASA classification & & \\
$\quad 1$ & $71(69.6)$ & $57(58.8)$ \\
2 & $31(30.4)$ & $40(41.2)$ \\
Systolic blood pressure $(\mathrm{mmHg})$ & $135.6 \pm 20.2$ & $128.7 \pm 17.5$ \\
Diastolic blood pressure $(\mathrm{mmHg})$ & $80.9 \pm 10.2$ & $77.0 \pm 11.7$ \\
Heart rate (beat/min) & $80.2 \pm 14.5$ & $76.2 \pm 11.3$ \\
\hline Da
\end{tabular}

Data are presented as means \pm SD or numbers (\%)

ASA American Society of Anesthesiologists

significantly increased initially (albeit slightly) then gradually decreased as the $\mathrm{F}_{\mathrm{A}} \mathrm{S}$ increased in both groups $(p<$ 0.001 for all parameters) (Fig. 5).

\section{Discussion}

Sevoflurane is a popular and widely used volatile anesthetic because it does not irritate the airway, hence it can be used as an induction agent, especially in children. Moreover, its low blood and fat solubility leads to rapid onset, easy depth of anesthesia adjustment, and early recovery [6]. Due to its high cost, however, LFA is used to reduce the amount needed [7]. The more important reasons to implement sevoflurane LFA are benefits to environment and mucociliary function of the patient [1]. Previously, the recommended lowest FGF to be used with sevoflurane was $1 \mathrm{~L} \cdot \mathrm{min}^{-1}$ for exposures up to $1 \mathrm{~h}$ and $2 \mathrm{~L} \cdot \mathrm{min}^{-1}$ for exposures $>1 \mathrm{~h}$ because of compound A concern [8]. With the introduction of strong base-free $\mathrm{CO}_{2}$ absorbents (e.g., Amsorb Plus and Litholyme), the issue with compound A from sevoflurane has been resolved and sevoflurane can be safely used in LFA [9]. LFA, however, needs a wash-in phase to rapidly build up $\mathrm{F}_{\mathrm{A}} \mathrm{S}$ to the required target concentration. The wash-in can be achieved by (a) increasing FGF to reduce the time constant [10]; (b) increasing $\mathrm{F}_{\mathrm{V}} \mathrm{S}$ to induce a concentration effect [11]; or (c) integrating both methods.

A few studies have addressed the wash-in technique for sevoflurane LFA. Lindqvist et al. reported a 2-step wash-in technique to achieve a $\mathrm{F}_{\mathrm{A}} \mathrm{S}$ of $1.2 \%$; starting with FGF $1 \mathrm{~L} \cdot \mathrm{min}^{-1}$ and $\mathrm{F}_{\mathrm{V}} \mathrm{S} 8 \%$ for $1 \mathrm{~min}$, then reducing FGF to $1,0.7,0.5$, and $0.3 \mathrm{~L} \cdot \mathrm{min}^{-1}$. They found that the respective time to achieve the target $\mathrm{F}_{\mathrm{A}} \mathrm{S}$ was 1.8, 1.5, 2.5 , and $3.6 \mathrm{~min}$ [3]. Horwitz et al. reported that by using a FGF of 1.0 or $0.5 \mathrm{~L} \cdot \mathrm{min}^{-1}$ with a $\mathrm{F}_{\mathrm{V}} \mathrm{S} 6 \%$ during the wash-in, the respective time to reach 1 MAC was $6.2 \pm$ 1.3 and $15.2 \pm 2.4 \mathrm{~min}$ and up to $1.5 \mathrm{MAC}$ at $7.5 \pm 2.5$ and $19 \pm 4.4 \mathrm{~min}$ [4]. The limitation of these two schemes is that they cover only 1 or $2 \mathrm{~F}_{\mathrm{A}} \mathrm{S}$ targets, and hence cannot be applied for other required $\mathrm{F}_{\mathrm{A}} \mathrm{S}$ targets.

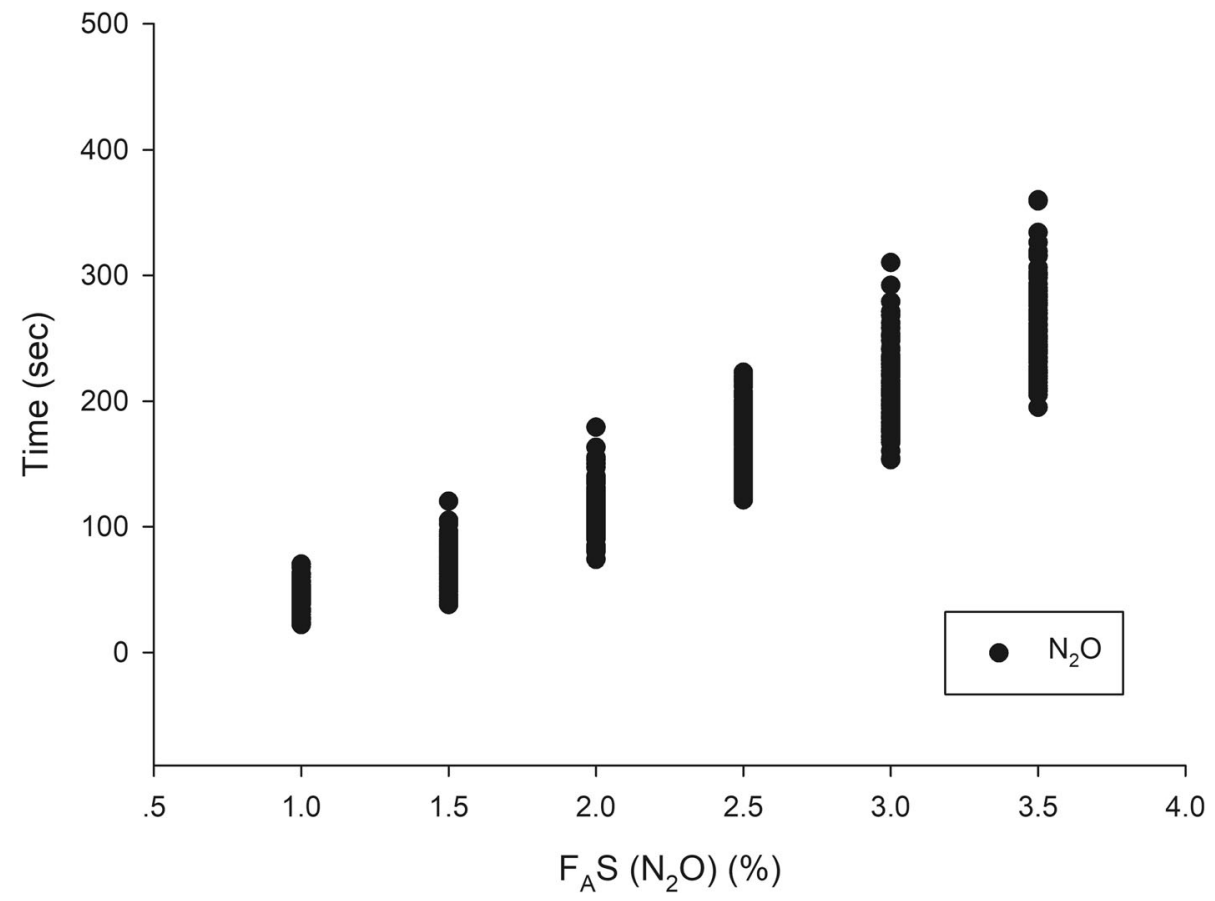

Fig. 1 Trajectories of $F_{A} S$ vs. time to achieve each $F_{A} S$ during wash-in of group $N_{2} O$. $F_{A} S$, alveolar concentration of sevoflurane 


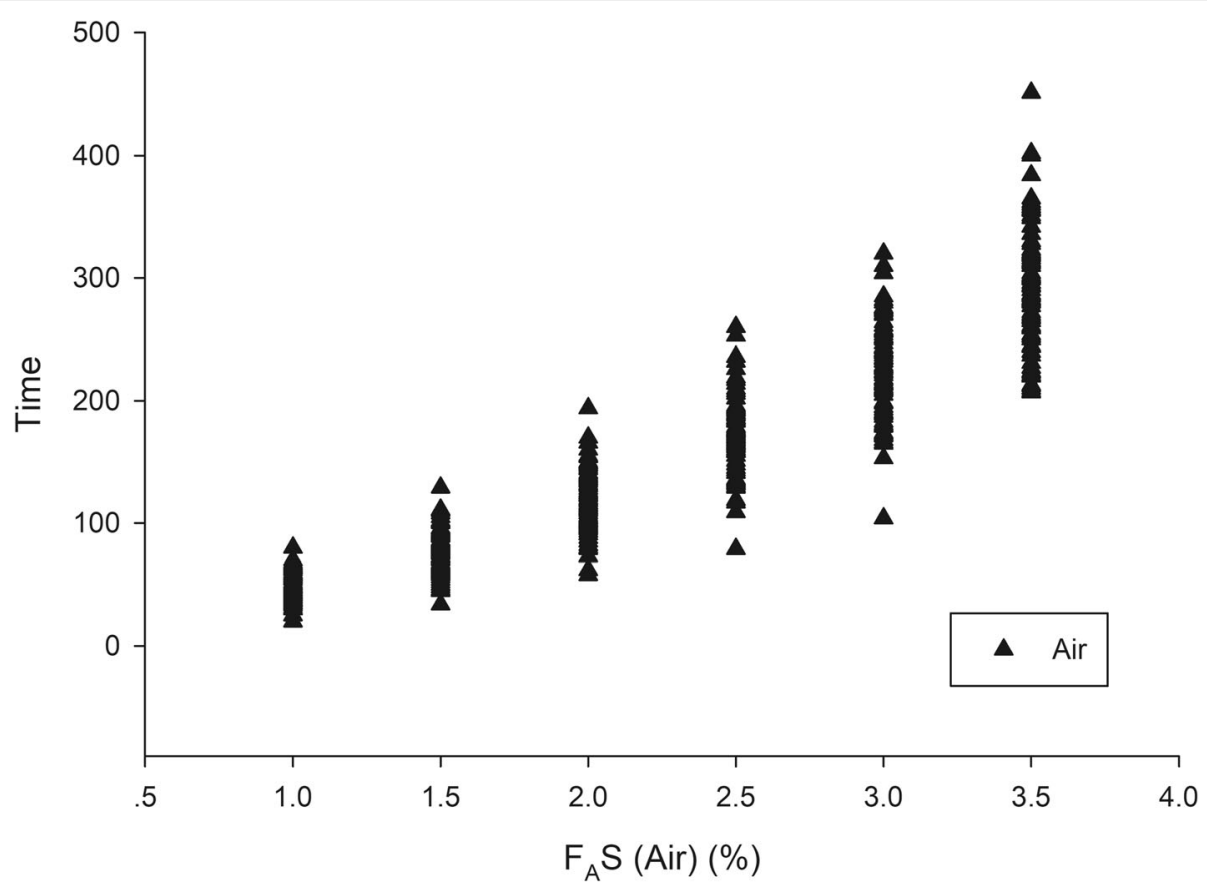

Fig. 2 Trajectories of $F_{A} S$ vs. time to achieve each $F_{A} S$ during wash-in of group Air. $F_{A} S$, alveolar concentration of sevoflurane

Jakobsson et al. reported a wash-in in a test-lung model with a respective FGF of 0.3 and $4 \mathrm{~L} \cdot \mathrm{min}^{-1}$ and a $\mathrm{F}_{\mathrm{V}} \mathrm{S}$ of $8 \%$. They found that the $\mathrm{F}_{\mathrm{A}} \mathrm{S}$ reached $1 \mathrm{MAC}(2.1 \%)$ at $547 \pm 83$ and $38 \pm 6 \mathrm{~s}$, respectively [5]. Leijonhufvud et al. reported a wash-in in a test-lung using a respective FGF of $1,2,4,4.8,6$, and $8 \mathrm{~L} \cdot \mathrm{min}^{-1}$ and a $\mathrm{F}_{\mathrm{V}} \mathrm{S} 6 \%$ in a Flow-I and a Aisys anesthetic machine. They found that the respective mean time to achieve 1 MAC was 431.3, 185.6, $66,53.6,53.6$, and $52.6 \mathrm{~s}$ for the Flow-I and 262.7, 144.3, $57.7,52.3,57.7$, and $58.3 \mathrm{~s}$ for the Aisys [12]. Finally, Shin

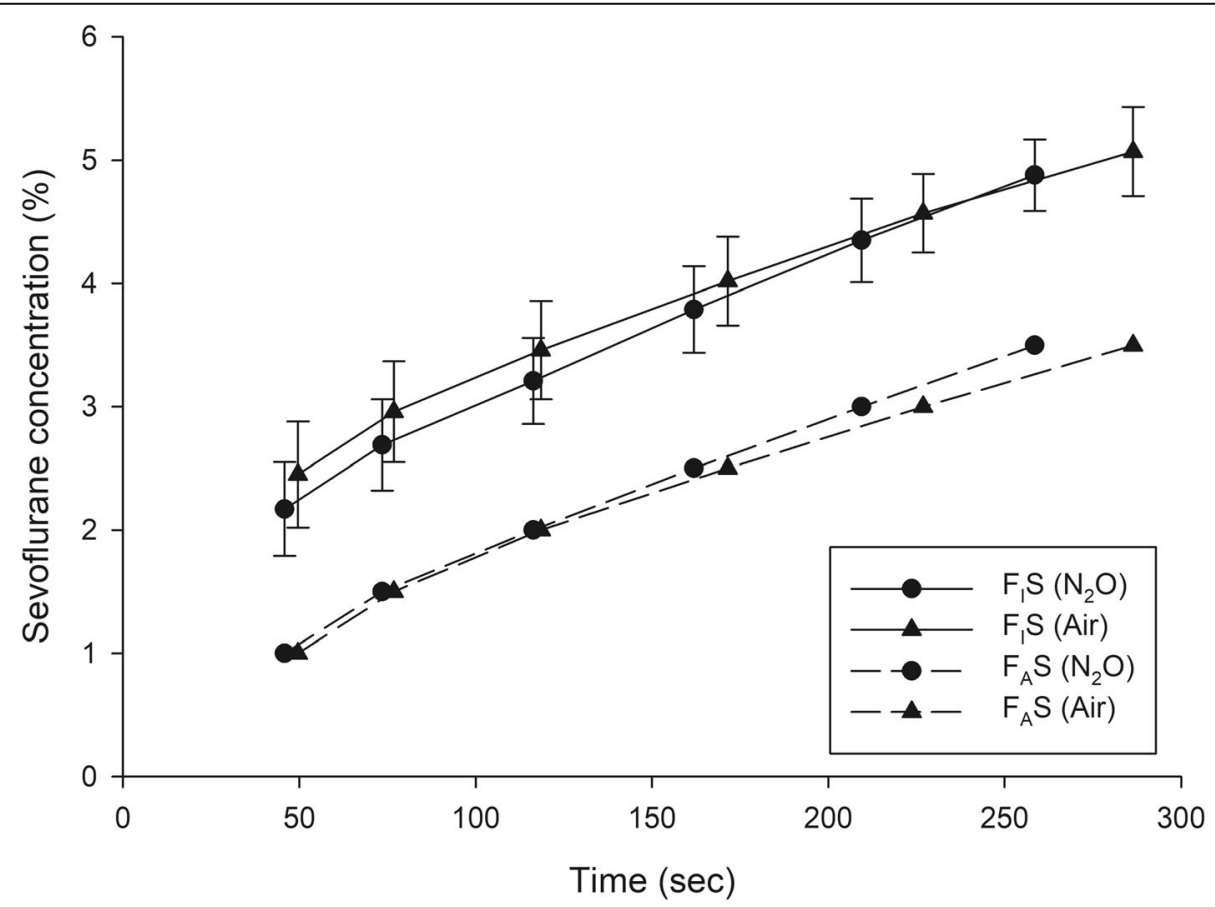

Fig. 3 Rising pattern of $F_{A} S$ and $F_{F} S$ of group $N_{2} O$ and group Air. $F_{A} S$, alveolar concentration of sevoflurane; $F_{1} S$, inspired concentration of sevoflurane 


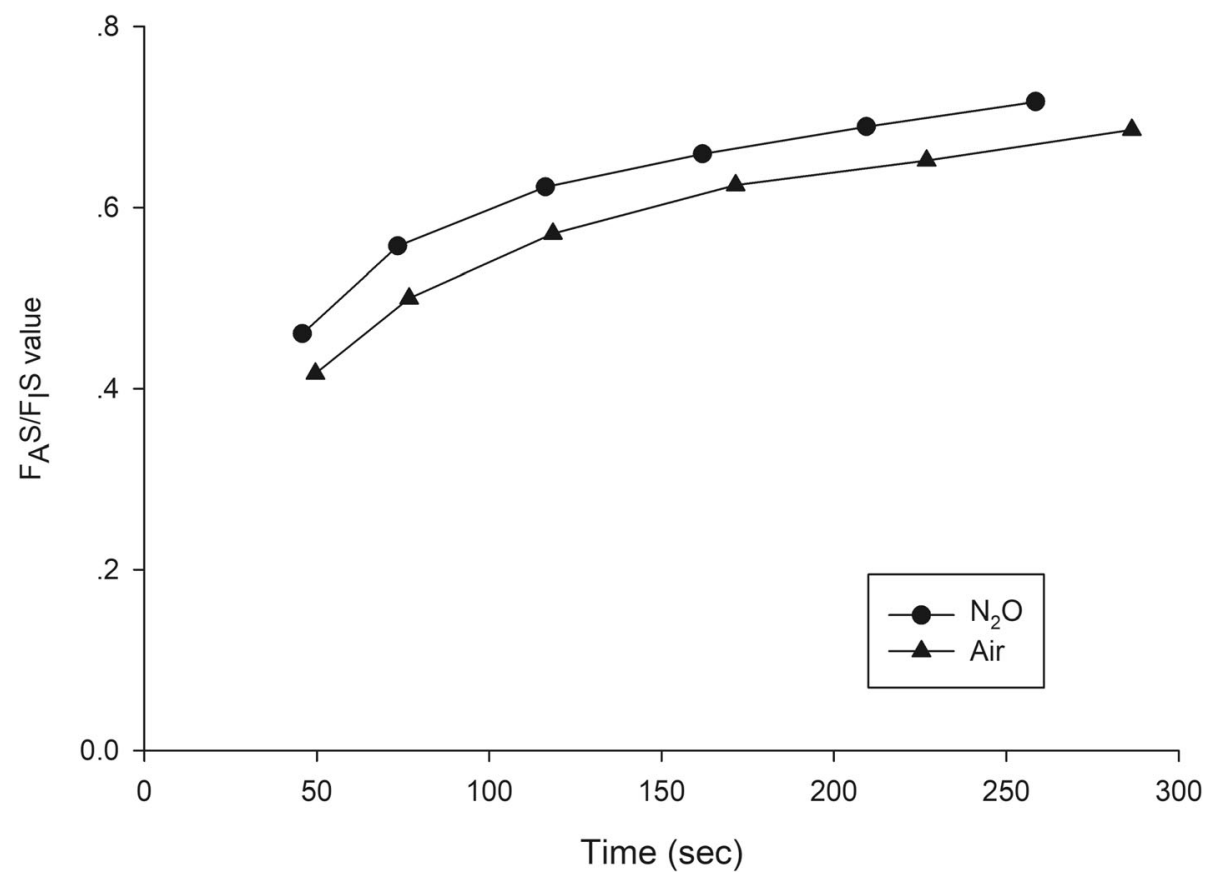

Fig. 4 Rising pattern of $F_{A} S / F_{1} S$ ratio of group $N_{2} O$ and group Air. $F_{A} S$, alveolar concentration of sevoflurane; $F_{1} S$, inspired concentration of sevoflurane

et al. performed a wash-in study using a Primus anesthetic machine connected to a test-lung, using a FGF of $0.5,1$, and $3 \mathrm{~L} \cdot \mathrm{min}^{-1}$ and setting the $\mathrm{F}_{\mathrm{V}} \mathrm{S}$ to $6 \%$. The respective mean time to reach a $F_{\mathrm{A}} \mathrm{S}$ of $4 \%$ for each FGF was 1165 , 534 , and $155 \mathrm{~s}$ [13]. The latter 3 studies were, however, all performed in test-lungs such that the uptake of sevoflurane by body tissues was not considered, so the results cannot be generalized to clinical practice.

The current study proposed a 1-1-8 wash-in scheme for sevoflurane LFA using $\mathrm{N}_{2} \mathrm{O}$ or Air-which can rapidly and predictably achieve each $\mathrm{F}_{\mathrm{A}} \mathrm{S}$ (i.e., 1 to $3.5 \%$ as is used in daily practice within 4.5 and $5 \mathrm{~min}$, respectively). The time to achieve every $F_{A} S$ was identical for both groups except at $\mathrm{F}_{\mathrm{A}} \mathrm{S}$ of 3 and $3.5 \%$ where the time in group Air was a nominally longer than group $\mathrm{N}_{2} \mathrm{O}$ because of the second gas effect of $\mathrm{N}_{2} \mathrm{O}$ [11]. When this wash-in scheme uses $\mathrm{O}_{2}$ : $\mathrm{N}_{2} \mathrm{O} 1: 1 \mathrm{~L} \cdot \mathrm{min}^{-1}$ as the carrier gases, $50 \% \mathrm{~N}_{2} \mathrm{O}$ provides
0.5 MAC in addition to the MAC of sevoflurane [14], hence this protocol can further reduce the use of sevoflurane. When $\mathrm{N}_{2} \mathrm{O}$ is contraindicated or Air is preferred, a higher $\mathrm{F}_{\mathrm{A}} \mathrm{S}$ is required, and yet this wash-in scheme consistently, precisely, and promptly achieves the required target.

Comparing with a similar 1-1-12 wash-in scheme for desflurane LFA which uses desflurane 12\% (2 MAC) [15, 16], the current 1-1-8 sevoflurane wash-in scheme uses a higher MAC ( $8 \%$ or 4 MAC) of sevoflurane. The reasons are that (a) sevoflurane has greater blood and fat solubility than desflurane, leading to higher body tissue uptake, which results in a longer time to achieve an equivalent MAC; and, (b) sevoflurane has a 3 times lower MAC value, hence 4 MAC of sevoflurane was used to augment a concentration effect [11].

The trajectories of the times to achieve each $\mathrm{F}_{\mathrm{A}} \mathrm{S}$ in both groups (Figs. 1 and 2) suggests that the tested wash-in

Table 2 Actual time in seconds with $95 \% \mathrm{Cl}$ and approximate upper $\mathrm{Cl}$ limit time in minutes to achieve each $\mathrm{F}_{\mathrm{A}} \mathrm{S}$ in group $\mathrm{N}_{2} \mathrm{O}$ $(n=102)$

\begin{tabular}{lllll}
\hline$F_{\mathrm{A}} \mathrm{S}(\%)$ & $\mathrm{F}_{\mathrm{S}}(\%)$ & Time $(\mathrm{sec})$ & $95 \% \mathrm{Cl}(\mathrm{sec})$ & Approximated upper Cl limit time (min) \\
\hline 1 & 2.2 & $45.8 \pm 9.8$ & $43.9-47.8$ & 1 \\
1.5 & 2.7 & $73.5 \pm 14.5$ & $70.7-76.4$ & 1.5 \\
2 & 3.2 & $116.3 \pm 20.4$ & $112.3-120.3$ & 2 \\
2.5 & 3.8 & $161.9 \pm 23.3$ & $157.3-166.4$ & 3 \\
3 & 4.4 & $208.4 \pm 30.6$ & $202.4-214.4$ & 3.5 \\
3.5 & 4.9 & $258.5 \pm 35.0$ & $251.7-265.4$ & 4.5 \\
\hline
\end{tabular}

Data are presented as means \pm SD or ranges

$F_{F} S$ inspired concentration of sevoflurane, $F_{A} S$ alveolar concentration of sevoflurane, $\mathrm{Cl}$ confidence interval 
Table 3 Actual time in seconds with 95\% Cl and approximate upper $\mathrm{Cl}$ limit time in minutes to achieve each $\mathrm{F}_{\mathrm{A}} \mathrm{S}$ in group Air $(n=$ 97)

\begin{tabular}{lllll}
\hline$F_{\mathrm{A}} \mathrm{S}(\%)$ & $\mathrm{F}_{\mathrm{S}}(\%)$ & Time $(\mathrm{sec})$ & $95 \% \mathrm{Cl}(\mathrm{sec})$ & Approximated upper Cl limit time (min) \\
\hline 1 & 2.4 & $49.6 \pm 10.9$ & $47.4-51.8$ & 1 \\
1.5 & 3.0 & $76.8 \pm 16.5$ & $73.5-80.2$ & 1.5 \\
2 & 3.5 & $118.5 \pm 24.0$ & $113.6-123.3$ & 2 \\
2.5 & 4.0 & $171.5 \pm 30.5$ & $165.4-177.7$ & 3 \\
3.5 & 4.6 & $226.9 \pm 38.4$ & $219.1-234.6$ & 4 \\
\hline
\end{tabular}

Data are presented as means \pm SD or ranges

$F, S$ inspired concentration of sevoflurane, $F_{A} S$ alveolar concentration of sevoflurane, $\mathrm{Cl}$ confidence interval

scheme has acceptable intra- and inter-subject variability. The parallel rising pattern of $F_{A} S$ and $F_{I} S$ (Fig. 3) shows that the wash-in scheme has enough power to drive both $\mathrm{F}_{\mathrm{A}} \mathrm{S}$ and $\mathrm{F}_{\mathrm{I}} \mathrm{S}$ to the desired target of both groups within 4.5 and $5 \mathrm{~min}$, as reflected in the rising $\mathrm{F}_{\mathrm{A}} \mathrm{S} / \mathrm{F}_{\mathrm{I}} \mathrm{S}$ ratio pattern (Fig. 4). The rising $F_{A} / F_{I}$ ratio pattern reflects the onset of volatile anesthetic: the more rapid the rise the shorter the onset. The rapidly rising $\mathrm{F}_{\mathrm{A}} \mathrm{S} / \mathrm{F}_{\mathrm{I}} \mathrm{S}$ ratio of the 1-1-8 wash-in scheme in both groups underscores the efficacy of this scheme. The higher $\mathrm{F}_{\mathrm{A}} \mathrm{S} / \mathrm{F}_{\mathrm{I}} \mathrm{S}$ ratio of the group $\mathrm{N}_{2} \mathrm{O}$ reflects the second gas effect [11].

The changes in heart rate and blood pressure during the wash-in process are similar to the 1-1-12 wash-in scheme for desflurane $[15,16]$ (i.e., slightly increasing initially then gradually decreasing as presented in Fig. 5). The changes are statistically but not clinically significant.
The 1-1-8 wash-in scheme has many advantages: (a) simplicity - just a one-step setting; (b) coverage - includes every $\mathrm{F}_{\mathrm{A}} \mathrm{S}$ target from 1 to $3.5 \%$ used in daily practice both in balanced anesthesia and pure inhalation anesthesia; (c) swiftness - accomplishing the desired target within 1 to 4.5 or $5 \mathrm{~min}$; (d) safety - no clinically significant change in heart rate and blood pressure; (e) economy - just 2 $\mathrm{L} \cdot \mathrm{min}^{-1}$ of FGF; and (f) applicability - can be applied with both $\mathrm{N}_{2} \mathrm{O}$ and Air. When the target $\mathrm{F}_{\mathrm{A}} \mathrm{S}$ is achieved, the FGF can be reduced to $1 \mathrm{~L} \cdot \min ^{-1}$ and the $\mathrm{F}_{\mathrm{A}} \mathrm{S}$ can simply be maintained by setting the $\mathrm{F}_{\mathrm{V}} \mathrm{S}$ above the desired $\mathrm{F}_{\mathrm{A}} \mathrm{S}$ by 50 to $60 \%$ [17]. The current study used Litholyme as the $\mathrm{CO}_{2}$ absorbent to guarantee the safety of sevoflurane LFA.

Most hospitals in developed countries have an anesthetic gas analyzer in the operating theatre, making any wash-in scheme unnecessary during low-flow

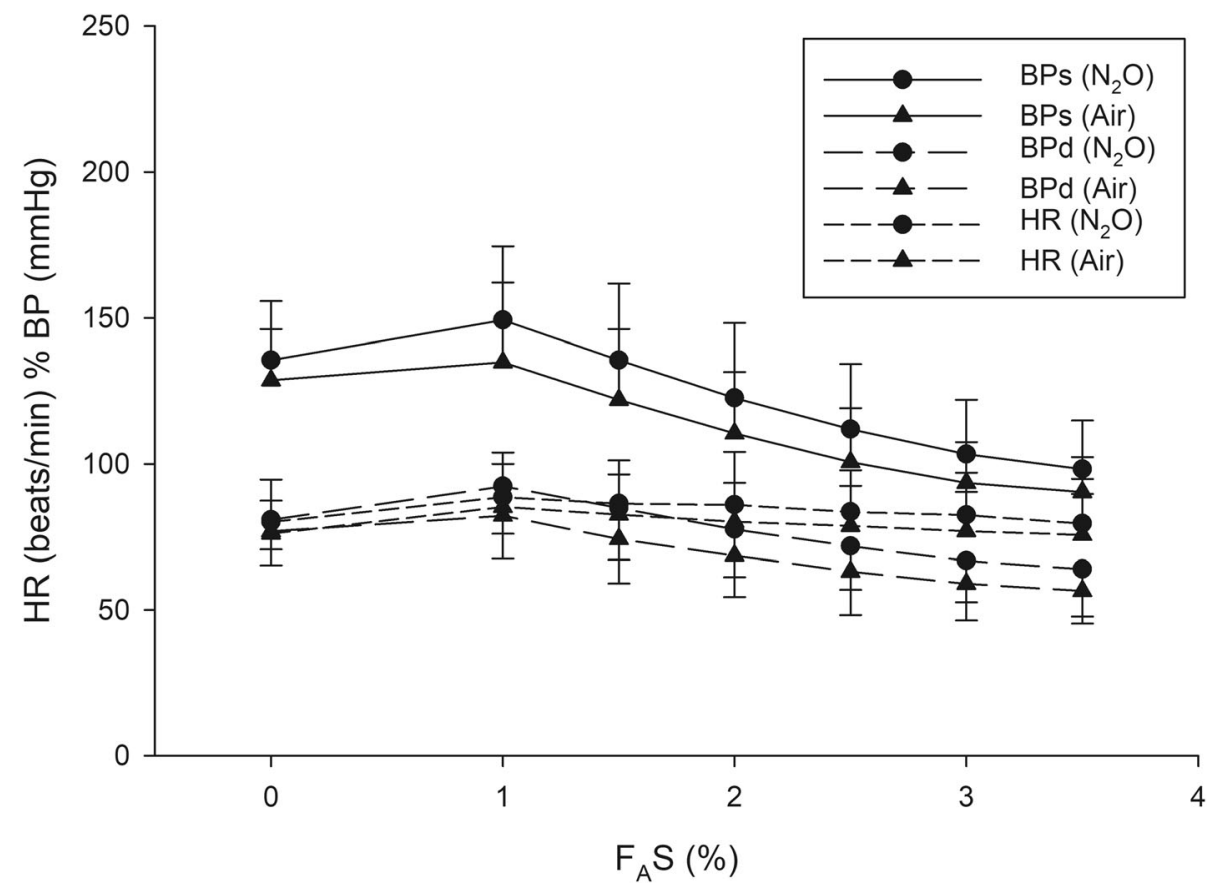

Fig. 5 Pattern of changes in heart rate and blood pressure of group $N_{2} O$ and group Air at each $F_{A} S . p<0.001$ for all values. $F_{A} S$, alveolar concentration of sevoflurane; BPs, systolic blood pressure; BPd, diastolic blood pressure; HR, heart rate 
anesthesia. Many operating theatres in less developed areas, however, still lack such equipment. The tested wash-in scheme may thus be applied as guidance to perform sevoflurane LFA provided that an inspired oxygen concentration monitor is available.

\section{Limitations}

Since we excluded patients with a BMI $>30 \mathrm{~kg} \mathrm{~m}^{-2}$; having pulmonary or cardiac disease; or, being pregnant, this wash-in scheme may not be applied in those groups of patients. Further studies are required.

\section{Conclusions}

In patients requiring general anesthesia with endotracheal intubation and controlled ventilation, the 1-1-8 wash-in scheme for sevoflurane LFA yields a respective $\mathrm{F}_{\mathrm{A}} \mathrm{S}$ of 1 , $1.5,2,2.5,3$, and $3.5 \%$ at $1,1.5,2,3,3.5$, and $4.5 \mathrm{~min}$ when used with $\mathrm{N}_{2} \mathrm{O}$ and at $1,1.5,2,3,4$, and 5 min when used with Air. This technique uses a one-step setting for $\mathrm{O}_{2}$ : $\mathrm{N}_{2} \mathrm{O}$ or $\mathrm{O}_{2}$ :Air $1: 1 \mathrm{~L} \cdot \mathrm{min}^{-1}$ with sevoflurane $8 \%$. There were statistically but not clinically significant changes in heart rate and blood pressure during the wash-in process.

\section{Abbreviations}

ASA: American Society of Anesthesiologists; Cl: Confidence interval; $\mathrm{CO}_{2}$ : Carbon dioxide; $\mathrm{F}_{\mathrm{A}} \mathrm{S}$ : Alveolar concentration of sevoflurane; FGF: Fresh gas flow; $F_{1} S$ : Inspired concentration of sevoflurane; $F_{V}$ : Vaporizer concentration of volatile anesthetic; $F_{V} S$ : Vaporizer concentration of sevoflurane; $\mathrm{N}_{2} \mathrm{O}$ : Nitrous oxide; $\mathrm{O}_{2}$ : Oxygen; SD: Standard deviation

\section{Acknowledgments}

We thank Bryan Roderick Hamman for assistance with the English-language presentation of the manuscript under the aegis of the Publication Clinic KKU, Thailand.

\section{Authors' contributions}

ST and TS designed the study, performed the study, performed the statistical analysis and wrote the manuscript. NV, MT, DN, and WS performed the study and collected data. All authors read and approved the final manuscript.

\section{Funding}

The study was funded by an unrestricted University grant from Faculty of Medicine, Khon Kaen University, Khon Kaen, Thailand (Grant number: IN59221). The funding body had no role in the design of the study or collection, analysis, and interpretation of the data, or in writing the manuscript.

\section{Availability of data and materials}

The data used to support the findings of this study are available from the corresponding author upon request.

\section{Ethics approval and consent to participate}

The current study was approved by the Khon Kaen University Ethics Committee in Human Research (HE601228). All participants gave written informed consent before being recruited into the study.

\section{Consent for publication}

Not applicable.

\section{Competing interests}

The authors declare that they have no competing interests.
Received: 23 September 2019 Accepted: 15 January 2020

Published online: 24 January 2020

\section{References}

1. Baum JA. Low-flow anesthesia: theory, practice, technical preconditions, advantages, and foreign gas accumulation. J Anesth. 1999;13:166-74.

2. Nickalls RW, Mapleson WW. Age-related iso-MAC charts for isoflurane, sevoflurane and desflurane in man. Br J Anaesth. 2003;91:170-4.

3. Lindqvist $M$, Jakobsson J. Minimal flow anesthesia for short elective day case surgery; high vaporiser settings are needed but still cost-effective. Ambul Surg. 2011;17:27-9.

4. Horwitz M, Jakobsson JG. Desflurane and sevoflurane use during low- and minimal-flow anesthesia at fixed vaporizer settings. Minerva Anestesiol. 2016;82:180-5 PMID: 26198766.

5. Jakobsson $P$, Lindgren $M$, Jakobsson JG. Wash-in and wash-out of sevoflurane in a test-lung model: A comparison between Aisys and FLOW-i. F1000Res. 2017:6:389.

6. Young CJ, Apfelbaum JL. Inhalational anesthetics: desflurane and sevoflurane. J Clin Anesth. 1995;7:564-77.

7. Ryu HG, Lee JH, Lee KK, Gil NS, Kim CS, Sim SE, et al. The effect of low fresh gas flow rate on sevoflurane consumption. Korean J Anesthesiol. 2011;60:75-7.

8. Gentz BA, Malan TP Jr. Renal toxicity with sevoflurane: a storm in a teacup? Drugs. 2001;61:2155-62.

9. Marini F, Bellugi I, Gambi D, Pacenti M, Dugheri S, Focardi L, et al. Compound A, formaldehyde and methanol concentrations during low-flow sevoflurane anesthesia: comparison of three carbon dioxide absorbers. Acta Anaesthesiol Scand. 2007;51:625-32.

10. Honemann C, Hagemann O, Doll D. Inhalational anesthesia with low fresh gas flow. Indian J Anesth. 2013;57:345-50.

11. Korman B, Mapleson WW. Concentration and second gas effects: can the accepted explanation be improved? Br J Anesth. 1997:78:618-25.

12. Leijonhufvud F, Joneby F, Jakobsson JG. The impact of fresh gas flow on wash-in, wash-out time and gas consumption for sevoflurane and desflurane, comparing two anesthesia machines, a test-lung study. F1000Res. 2017;6:1997.

13. Shin HW, Yu HN, Bae GE, Huh H, Park JY, Kim JY. The effect of fresh gas flow rate and type of anesthesia machine on time to reach target sevoflurane concentration. BMC Anesthesiol. 2017;17:10.

14. Vereecke HEM, Proost JH, Heyse B, Eleveld DJ, Katoh T, Luginbühl M, et al. Interaction between nitrous oxide, sevoflurane, and opioids: a response surface approach. Anesthesiology. 2013;118:894-902.

15. Sathitkarnmanee T, Tribuddharat S, Suttinarakorn C, Nonlhaopol D, Thananun M, Somdee W, et al. 1-1-12 one-step wash-in scheme for desflurane-nitrous oxide low-flow anesthesia: rapid and predictable induction. Biomed Res Int. 2014;2014:867504.

16. Sathitkarnmanee T, Tribuddharat S, Nonlhaopol D, Thananun M, Somdee W. 1-1-12 one-step wash-in scheme for desflurane low flow anesthesia: performance without nitrous oxide. Drug Des Devel Ther. 2015:9:977-81.

17. Hargasser S, Hipp R, Breinbauer B, Mielke L, Entholzner E, Rust M. A lower solubility recommends the use of desflurane more than isoflurane, halothane, and enflurane under low-flow conditions. J Clin Anesth. 1995;7:49-53.

\section{Publisher's Note}

Springer Nature remains neutral with regard to jurisdictional claims in published maps and institutional affiliations.
Ready to submit your research? Choose BMC and benefit from:
- fast, convenient online submission
- thorough peer review by experienced researchers in your field
- rapid publication on acceptance
- support for research data, including large and complex data types
- gold Open Access which fosters wider collaboration and increased citations
- maximum visibility for your research: over $100 \mathrm{M}$ website views per year
At BMC, research is always in progress.
Learn more biomedcentral.com/submissions 